\title{
Consistent and contrasting decadal Arctic sea ice thickness predictions from a highly optimized sea ice model
}

Article

Published Version

Miller, P. A., Laxon, S. W. and Feltham, D. L. (2007)

Consistent and contrasting decadal Arctic sea ice thickness predictions from a highly optimized sea ice model. Journal of Geophysical Research, 112 (C7). C07020. ISSN 0148-0227 doi: https://doi.org/10.1029/2006JC003855 Available at https://centaur.reading.ac.uk/34745/

It is advisable to refer to the publisher's version if you intend to cite from the work. See Guidance on citing.

Published version at: http://dx.doi.org/10.1029/2006JC003855

To link to this article DOI: http://dx.doi.org/10.1029/2006JC003855

Publisher: American Geophysical Union

All outputs in CentAUR are protected by Intellectual Property Rights law, including copyright law. Copyright and IPR is retained by the creators or other copyright holders. Terms and conditions for use of this material are defined in the End User Agreement.

www.reading.ac.uk/centaur 
Central Archive at the University of Reading

Reading's research outputs online 


\section{Consistent and contrasting decadal Arctic sea ice thickness predictions from a highly optimized sea ice model}

Paul A. Miller, ${ }^{1,2}$ Seymour W. Laxon, ${ }^{1}$ and Daniel L. Feltham ${ }^{1,3}$
Received 1 August 2006; revised 23 March 2007; accepted 24 April 2007; published 18 July 2007.

[1] Decadal hindcast simulations of Arctic Ocean sea ice thickness made by a modern dynamic-thermodynamic sea ice model and forced independently by both the ERA-40 and NCEP/NCAR reanalysis data sets are compared for the first time. Using comprehensive data sets of observations made between 1979 and 2001 of sea ice thickness, draft, extent, and speeds, we find that it is possible to tune model parameters to give satisfactory agreement with observed data, thereby highlighting the skill of modern sea ice models, though the parameter values chosen differ according to the model forcing used. We find a consistent decreasing trend in Arctic Ocean sea ice thickness since 1979, and a steady decline in the Eastern Arctic Ocean over the full 40-year period of comparison that accelerated after 1980, but the predictions of Western Arctic Ocean sea ice thickness between 1962 and 1980 differ substantially. The origins of differing thickness trends and variability were isolated not to parameter differences but to differences in the forcing fields applied, and in how they are applied. It is argued that uncertainty, differences and errors in sea ice model forcing sets complicate the use of models to determine the exact causes of the recently reported decline in Arctic sea ice thickness, but help in the determination of robust features if the models are tuned appropriately against observations.

Citation: Miller, P. A., S. W. Laxon, and D. L. Feltham (2007), Consistent and contrasting decadal Arctic sea ice thickness predictions from a highly optimized sea ice model, J. Geophys. Res., 112, C07020, doi:10.1029/2006JC003855.

\section{Introduction}

[2] Recent studies have pointed to an Arctic sea ice cover that is undergoing rapid change. Sea ice extent has decreased since 1979 [Parkinson and Cavalieri, 2002], as has the perennial sea ice cover [Comiso, 2002], and the September sea ice cover reached extreme lows in 2002, 2003 and 2004 [Stroeve et al., 2005]. The length of the melt season over perennial sea ice is also increasing [Smith, 1998], a change that is worrying on account of the high negative correlation between the change in mean Arctic sea ice thickness in consecutive winters and the length of the intervening melt season [Laxon et al., 2003]. In addition, measurements of summer ice draft [Rothrock et al., 1999; Yu et al., 2004] have shown strong $30-40 \%$ reductions over a period of 40 years.

[3] A continuation of these trends in the decades to come would serve as an indicator of continued global warming, and, because of feedbacks such as the ice-albedo feedback mechanism, influence in turn the climate and physical environment of the northern hemisphere $(\mathrm{NH})$, with unpre-

\footnotetext{
${ }^{1}$ Centre for Polar Observation and Modelling, Department of Earth Sciences, University College London, London, UK.

${ }^{2}$ Now at Department of Physical Geography and Ecosystems Analysis, Lund University, Lund, Sweden.

${ }^{3}$ Also at British Antarctic Survey, Cambridge, UK.

Copyright 2007 by the American Geophysical Union. 0148-0227/07/2006JC003855
}

dictable consequences [Arctic Climate Impact Assessment, 2004].

[4] The simulations of NH sea ice in the General Circulation Models (GCM) contributing to the Fourth Assessment Report (AR4) of the Intergovernmental Panel on Climate Change (IPCC) have been analyzed in detail by Zhang and Walsh [2006]. Depending on the particular emissions scenario used, multimodel ensemble means show reductions of sea ice area of between $21.6 \%$ and $33.4 \%$ in the last 20 years of the 21 st century relative to the years 1979-1999. In addition, there are consistent and rapid reductions in multiyear sea ice area and an amplified season cycle due to an increased fraction of seasonal sea ice cover. Moreover, we can have more confidence in the accuracy of these predictions because of two factors. First, a large number of the AR4 models now realistically capture the variations in NH sea ice area between 1979 and 1999, including its observed climatological mean, seasonal cycle and decreasing trend [Zhang and Walsh, 2006]. Secondly, a substantial number of the AR4 models have now recently incorporated advances in the modeling of sea ice dynamics, such as [Zhang and Walsh, 2006, Table 1] the viscousplastic (VP) rheology [Hibler, 1979] or its numerically efficient variant, the elastic-viscous-plastic (EVP) rheology [Hunke and Dukowicz, 1997], the use of multiple thickness categories [Thorndike et al., 1975], and solution of the governing equations of motion in curvilinear coordinates [Hunke and Dukowicz, 2002]. 
[5] We can further assess the skill of modern sea ice models by forcing them with best estimates of atmospheric conditions and comparing the simulated ice with observed changes over the same period. However, even simpler, stand-alone sea ice and coupled ice-ocean models, which mostly ignore the complication of atmospheric feedbacks, differ greatly in their simulations of recent Arctic sea ice thickness changes. This was illustrated by Rothrock et al. [2003, Figure 12], who compared the mean annual Arctic ice thickness simulated by their coupled ice-ocean model with those of seven other published model simulations and found that not only did the mean thicknesses differ substantially but that the trends did also, with agreement improving only after 1980 . They were able to identify no immediately obvious reason for the large differences between models, but such intermodel differences, and indeed differences between models and observations, are likely due to errors in the forcing data, differing forcing data, different model resolutions, whether the model is coupled to an ocean model, model domain, different parameterizations and physical processes included in the models, and even different parameters used by models with identical parameterizations.

[6] This uncertainty makes it difficult to assess which sea ice model parameter values or parameterizations to use, or even what conclusions on the basis of their use to trust. However, one criterion in that assessment could be whether or not models can be shown to simulate the observations of Arctic sea ice that have become available in recent years to a satisfactory degree.

[7] In this paper we attempt to remove some of this uncertainty, in particular the forcing uncertainty, by attempting to identify consistent features in the predicted changes in Arctic sea ice thickness between 1962 and 2001 using the Los Alamos sea ice model, CICE [Hunke and Lipscomb, 2001], when it is forced by two widely used reanalysis data sets, but simultaneously constrained to agree with observed features of the sea ice. Since many simulations to date of the Arctic Ocean and its sea ice cover have used National Center of Environmental Prediction/National Center of Atmospheric Research (NCEP/NCAR) [Kalnay et al., 1996] reanalysis data as atmospheric forcing [see, e.g., Rothrock et al., 2003], it was a natural choice for one forcing data set. For the second, we used the recently released ECMWF ERA-40 atmospheric reanalysis data set [Simmons and Gibson, 2000].

\section{Model and Forcing}

[8] The Los Alamos sea ice model, CICE [Hunke and Lipscomb, 2001], includes many of the advances in sea ice modeling that are now being included in the sea ice components of modern GCMs [Zhang and Walsh, 2006, Table 1]. It has energy-conserving thermodynamics [Bitz and Lipscomb, 1999], a viscous-plastic rheology with artificial elasticity introduced to aid computation (the elastic-viscous-plastic (EVP) rheology) [Hunke and Dukowicz, 1997], and models the evolution of the ice thickness distribution [Thorndike et al., 1975] through the use of multiple ice categories. Here we run CICE on a rotated latitude-longitude grid with a resolution of $1^{\circ}$ in a domain consisting of the Arctic Ocean and its peripheral seas above $56^{\circ} \mathrm{N}$. There were 4 ice layers and one layer of snow in each of the 5 thickness categories. Further details of the model setup used are given by Miller et al. [2006].

[9] We first forced the model with a set consisting mostly of ECMWF ERA-40 atmospheric reanalysis data [Simmons and Gibson, 2000] (http://www.ecmwf.int/research/era/). Specifically, we used 6-hourly $10-\mathrm{m}$ winds, $2-\mathrm{m}$ air temperatures, $T_{\text {air }}$, and snowfall, as well as daily longwave and shortwave surface radiation. Since the ERA- $40 T_{\text {air }}$ regularly exceeded the freezing point over ice-covered grid cells in summer, we imposed an upper limit of $273.65 \mathrm{~K}$ whenever the ice concentration in a grid cell exceeded 0.15 [Flato, 1995]. Specific humidity is taken as an annual climatology from the POLar Exchange at the Sea Surface (POLES) sea ice model forcing set (http://psc.apl.washington.edu/POLES/), which was calculated [Zhang et al., 2000] using POLES sea level pressure and air temperature using the method of Parkinson and Washington [1979], but for ease of reference, this model run will henceforth be referred to as the ERA-40 forced model. The ERA-40 forced model is spun up for 12 years using 1962 forcing repeatedly, after which it simulates Arctic sea ice from 1962 to 2001 .

[10] We also forced the model with NCEP [Kalnay et al., 1996] reanalysis data, a forcing set used in most earlier model studies of the Arctic Ocean [see, e.g., Rothrock et al., 2003, and references therein). Specifically, we used daily 10-m winds, $2-\mathrm{m}$ air temperatures, $T_{\text {air }}$, (also with an imposed $273.65 \mathrm{~K}$ upper limit) and specific humidity. However, snowfall is taken from the monthly-varying, regionally constant Vowinckel and Orvig [1970] climatology, and the surface radiative fluxes are a 1962-2001 climatology of daily ERA-40 shortwave and longwave data, since a comparison of the two reanalysis data sets by Liu et al. [2005] showed the ERA-40 data to be in better agreement with SHEBA observations [Perovich et al., 1999] than NCEP reanalysis data. The NCEP forced model is spun up for 12 years using 1948 forcing repeatedly, after which it simulates Arctic sea ice from 1948 to 2004. (We note that this is not the same simulation period as that for the ERA-40 forced model, but to confirm that no biases were introduced in this way, we spun up the NCEP forced model in an identical manner to that of the ERA-40 forced model, and found that the time series of annually averaged sea ice thickness was nearly identical for the period 1962 to 2001.)

[11] Finally, a simple mixed layer model is used to calculate oceanic heat flux, and ice-ocean drag is calculated using prescribed, spatially varying, temporally constant ocean currents from the POLES sea ice model forcing set. No heat flux is added to the bottom of the mixed layer, though this has been shown in earlier studies [e.g., Zhang et al., 1998b] to be both spatially and temporally variable, and a possible cause of recently observed sea ice thickness decline. Nor do we consider lateral heat fluxes in this study, a fact which, as we discuss in section 3.1 below, leads us to limit the area over which the model results are analyzed to that where lateral heat transport plays a lesser role in the total oceanic heat flux. Running the sea ice model in uncoupled mode such as this reduces complicating oceanic reactions to changes in atmospheric forcing sets in the 


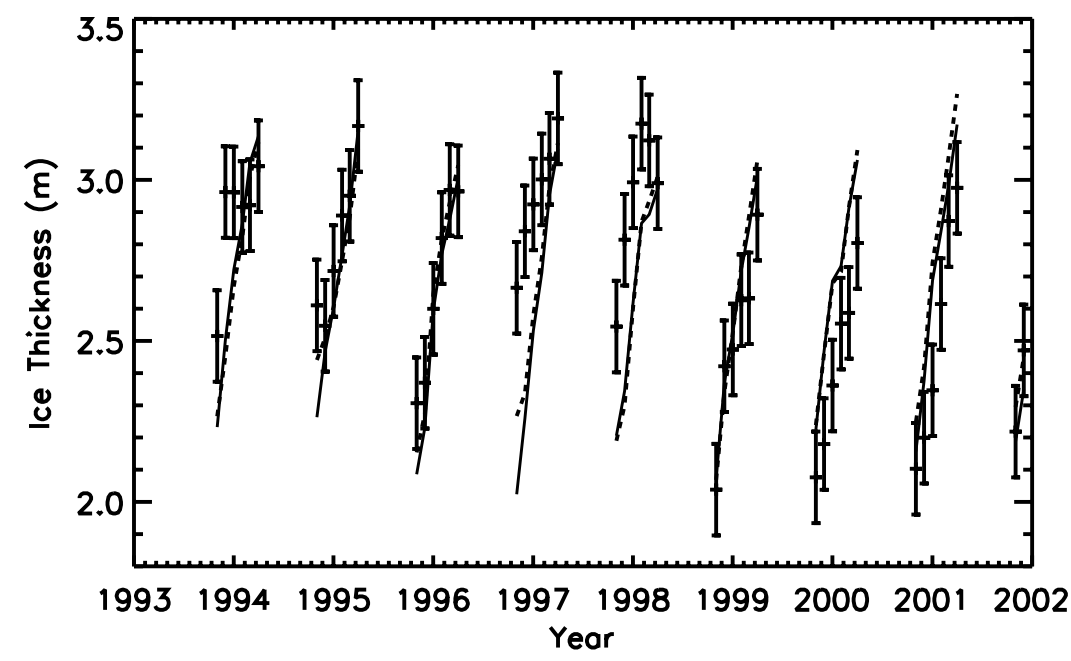

Figure 1. Monthly average sea ice thickness for the six winter months, November to April, below $81.5^{\circ} \mathrm{N}$ in the Arctic Basin region described in section 3.1, as observed [Laxon et al., 2003] (crosses), and as modeled by the ERA-40 (dotted line) and NCEP (solid line) models. $81.5^{\circ} \mathrm{N}$ is the northern observational limit of the ERS-1 and ERS-2 satellites carrying the radar altimeters, whose returns Laxon et al. [2003] used to derive the winter ice thickness. Ice thinner than $0.5 \mathrm{~m}$ was not included [Miller et al., 2006].

following analysis. Further details of the model parameterizations used are given by Miller et al. [2006].

\section{Model Validation}

\subsection{Validation Procedure}

[12] To tune and validate CICE we use satellite observations of sea ice thickness [Laxon et al., 2003], extent (calculated from sea ice concentration data [Cavalieri et $a l ., 2002]$ ) and speeds (calculated using the monthly sea ice velocity fields of Fowler [2003]) for the years 1993 to 2001 [Miller et al., 2006]. All comparisons were restricted to the central Arctic Ocean, henceforth referred to as the Arctic Basin. That is, we ignore the Barents and Greenland-IcelandNorwegian seas because stand-alone sea ice models typically predict excessive winter ice there owing to their lack of simulated lateral heat transport from the south [Hibler and Bryan, 1984], which keeps these seas free of ice throughout the year.

[13] CICE was independently tuned against these observations for both forcing sets by adopting a similar search of parameter space to that employed for CICE by Miller et al. [2006]. (There the model forcing was identical to that which we call here the ERA-40 forced model, except for the use of

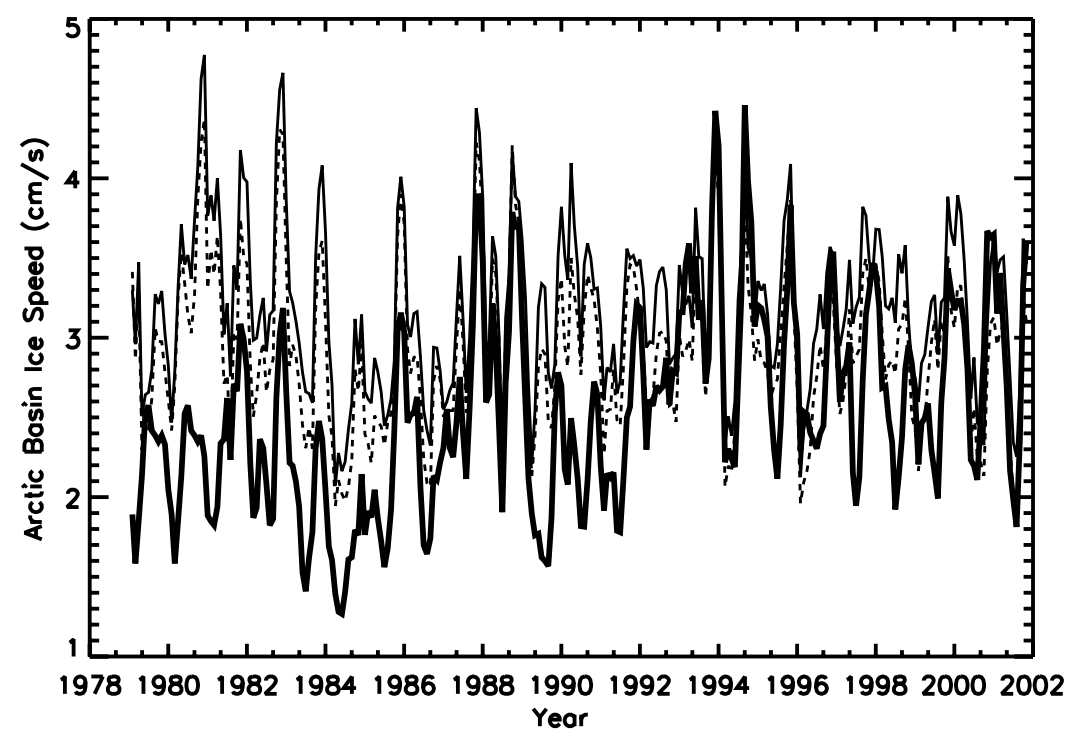

Figure 2. Three-month running mean $\left(\mathrm{cm} \mathrm{s}^{-1}\right)$ of Arctic Basin (see section 3.1) sea ice speeds from 1979 until 2001, as observed [Fowler, 2003] (thick solid line), and as modeled by the ERA-40 (dotted line, $R=0.67$ ), and NCEP (lighter solid line, $R=0.66$ ) models. After 1985 the correlations rise to $R=0.76$ and $R=0.75$, respectively. 


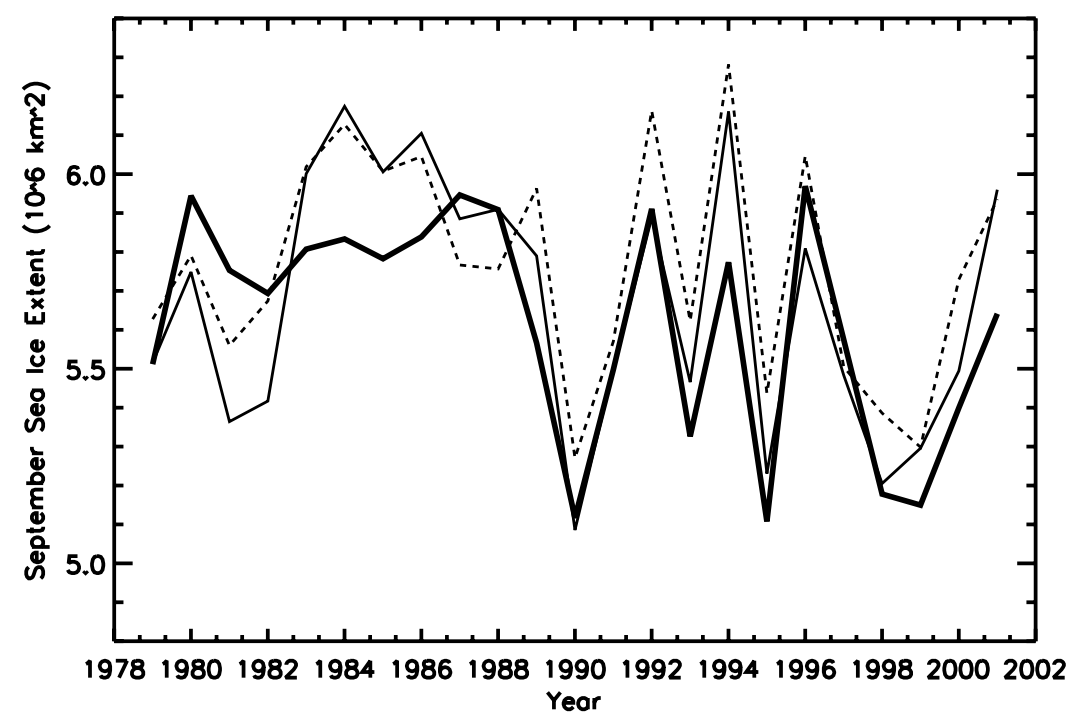

Figure 3. September Arctic Basin sea ice extent $\left(10^{6} \mathrm{~km}^{2}\right)$, as observed (thick solid line), and as modeled by the ERA-40 (dotted line, $R=0.77$, RMS $=0.24 \times 10^{6} \mathrm{~km}^{2}$ ) and NCEP (lighter solid line, $R=0.80, \mathrm{RMS}=0.20 \times 10^{6} \mathrm{~km}^{2}$ ) models. After 1985 the correlations rise to $R=0.81$ and $R=0.89$, respectively.

optimally interpolated IABP/POLES surface air temperatures [Rigor et al., 2000]. Unfortunately, the POLES data set begins in 1979, so we could not use these temperature observations in our 40-year model comparison.) A threedimensional parameter space was searched by varying three sea ice model parameters that each have a significant influence on modeled sea ice thickness, velocity and extent, yet whose values are uncertain, namely: the albedo of cold, thick ice, $\alpha$, in the CICE albedo parameterization [Hunke and Lipscomb, 2001]; the air drag parameter, $C_{a}$, when the air stress, $\tau_{\mathbf{a}}$, in the two-dimensional force balance is given by the simple quadratic parameterization

$$
\tau_{\mathbf{a}}=\rho_{a} C_{a}\left|\mathbf{u}_{\mathbf{a}}\right| \mathbf{u}_{\mathbf{a}},
$$

where $\mathbf{u}_{\mathbf{a}}$ is the $10-\mathrm{m}$ wind field; and the ice strength parameter, $P^{*}$, which arises in the simplified parameterization of grid cell ice strength, $P$, introduced by Hibler [1979],

$$
P=P^{*} h \exp \{-C(1-A)\},
$$

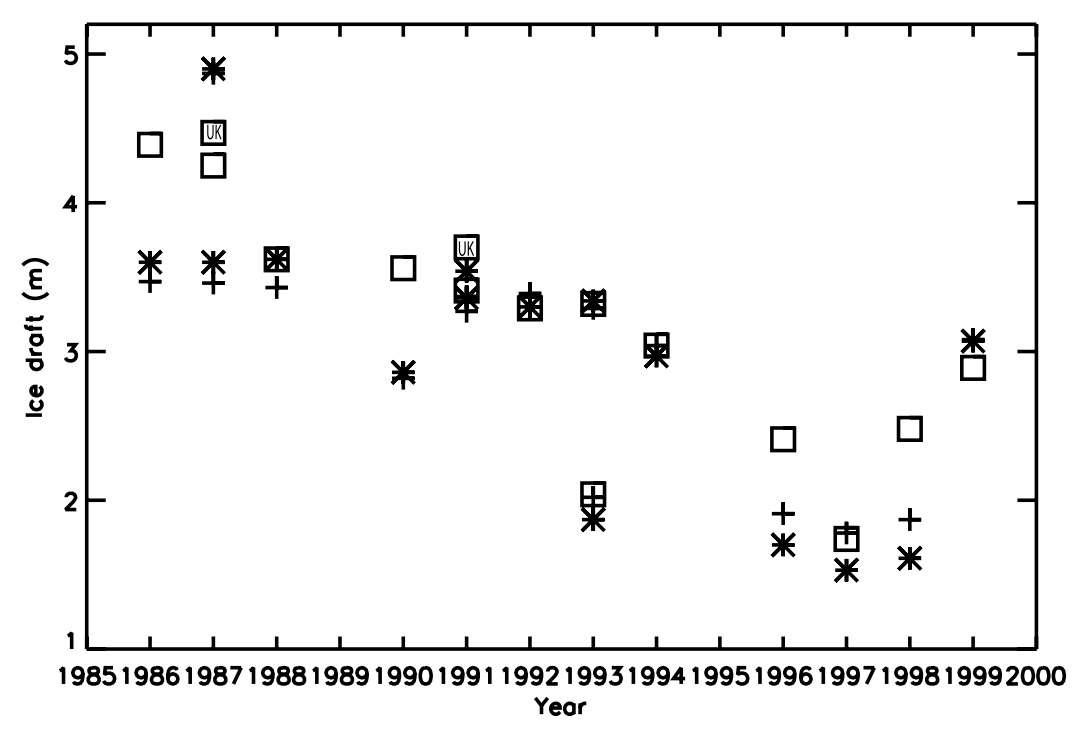

Figure 4. Mean sea ice draft for various cruises in the SCICEX box (see text). Squares: ULS means. Crosses: ERA-40 forced model (RMS $=0.45 \mathrm{~m}, R=0.89)$. Asterisks: NCEP forced model $(\mathrm{RMS}=0.46 \mathrm{~m}$, $R=0.91$ ). (There were two cruises in both 1987 and 1991, so U.K. cruises UK87 and UK91 are marked with U.K. in the square symbol. Both models overestimate the UK87 cruise average, but slightly underestimate the UK91 average draft.) There are 1568 linear sections over $10 \mathrm{~km}$, with a mean (standard deviation) of 2.8(1.0) $\mathrm{m}$. Modeled figures are: $2.68(0.93) \mathrm{m}$, RMS $=0.67 \mathrm{~m}, R=0.77$ (ERA-40 forced model), and 2.60(1.07) $\mathrm{m}, \mathrm{RMS}=0.70 \mathrm{~m}, R=0.79$ (NCEP forced model). 


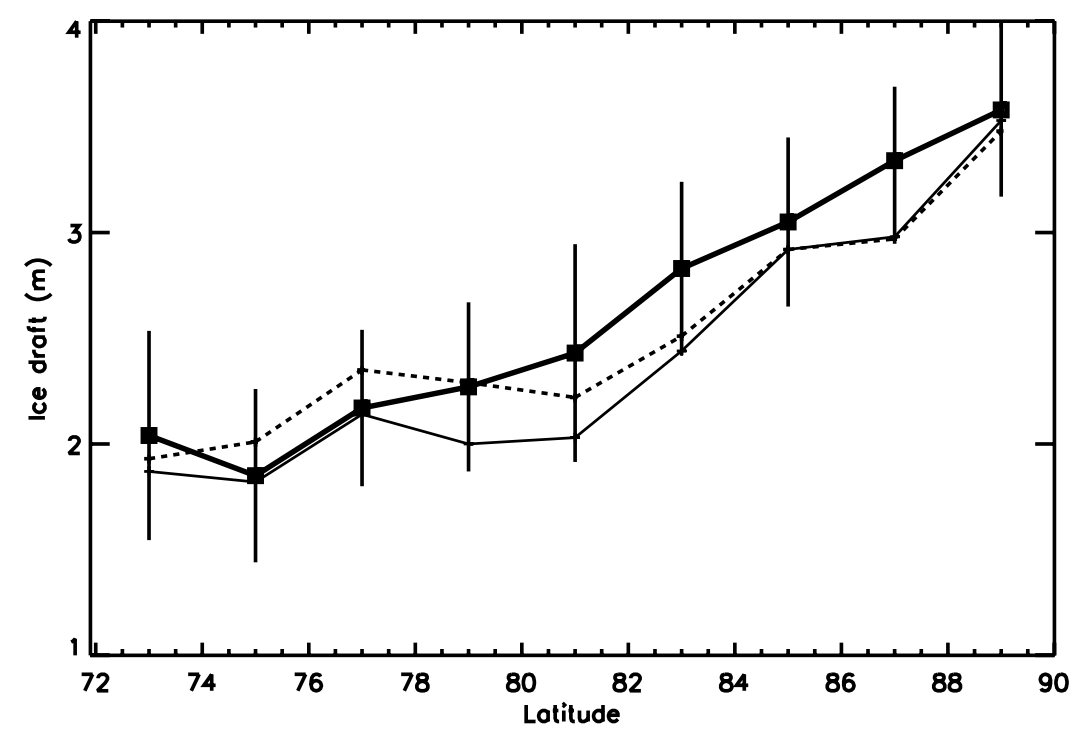

Figure 5. Mean sea ice draft in bins of $2^{\circ}$ latitude (see text). Thick solid line: ULS data, with the standard deviation of the observations indicated. Dotted line: ERA-40 forced model. Thin solid line: NCEP forced model.

where $C=20$ is a constant ice concentration parameter, $A$ is the ice area fraction in the grid cell, and $h$ is the mean ice thickness in the grid cell (volume per unit area of ice), here calculated using the ice thickness distribution with 5 thickness categories.

[14] In addition, we refined the tuning using an extended data set of digitally recorded upward looking sonar (ULS) sea ice draft observations from submarine cruises between 1986 and 1999. Comprising 1568 linear sections of $10 \mathrm{~km}$ or greater within a central Arctic Ocean region known as the SCICEX box [Rothrock et al., 2003], these data are available from the National Snow and Ice Data Center (NSIDC) (http://nsidc.org) with Cruise Reference Names: 1986b, 1987, UK-87 (Superb), 1988a, 1990, UK-91, 1991, L2-92, 1993, SCICEX-93, 1994, SCICEX-96, SCICEX-97, SCICEX-98 and SCICEX-99.

[15] Initial comparisons Miller et al. [2005] with a subset (comprising 850 linear sections) of these observations revealed, despite good agreement with observed velocities, summer ice extents and basin-scale thicknesses, a pronounced spatial discrepancy, namely modeled ice that was too thick near the Beaufort Sea and too thin near the North Pole. This error had also been noted by Rothrock et al. [2003], and, as noted by Lindsay and Zhang [2005], persists even when multidecadal observations of sea ice concentration and velocity are assimilated. However, Miller et al. [2005] found that this spatial discrepancy in modeled sea ice draft could be removed by reducing the squared ratio of the elliptical yield curve's major to minor axes, $e^{2}$, from its standard value [Hibler, 1979] of 4 to 0.5 . This change increases the ratio of shear to compressive strength of sea ice, perhaps even to an unrealistic degree, but Miller et al. [2005] interpret the improvements seen as indicating a need to have a larger relative shear stress than that predicted using the elliptical yield curve with $e=2$ during diverging or converging shear deformations. Wilchinsky et al. [2006] found that their new model of thickness redistribution during deformation led to an improved match with submarine-derived spatial distribution of ice thickness, however, this was not as effective as altering the aspect ratio of the elliptical yield curve employed by Miller et al. [2005]. We use $e^{2}=0.5$ in the simulations described below on account of the substantial improvements in sea ice thickness fields it yields. However, as we will show in section 5, this choice of yield curve shape does not greatly affect the trend in sea ice thickness, only the magnitude.

[16] Taking into account all observations, the optimal parameter set for the ERA-40 forced model was found to be $\left\{\alpha, C_{a}\right\}=\{0.62,0.00085\}$, whereas the optimal parameter set for the NCEP forced model was $\left\{\alpha, C_{a}\right\}=\{0.70$, $0.00135\}$. In both cases we find $P^{*}=6.25 \mathrm{kN} \mathrm{m}^{-2}$. Thus the optimal parameter values depend on the forcing set used but, apart from $e^{2}$, are still within the range of common usage [Miller et al., 2006]. We discuss these differences further in section 5 below.

\subsection{Validation Results}

[17] Figures 1-5 illustrate the models' agreement with both the satellite and submarine-derived observations. In particular we note the ability of each version of the model to capture the interannual variability of sea ice thickness and draft in Figures 1 and 4, respectively, as well as the improved spatial distribution of sea ice draft in Figure 5 [Miller et al., 2005].

[18] The 23-year time series of both sea ice speeds (Figure 2) and September ice extent (Figure 3) also illustrate the models' skill in capturing observed interannual variability, though in both cases we note the improvement in correlations after 1985, which is approximately when both sea ice draft observations and SSM/I data became available, and includes the period over which the model was tuned against the observations.

\section{Decadal Sea Ice Thickness Predictions 4.1. Mean Arctic Basin Predictions}

[19] With both versions of the model showing satisfactory agreement with an extensive and independent series of sea 


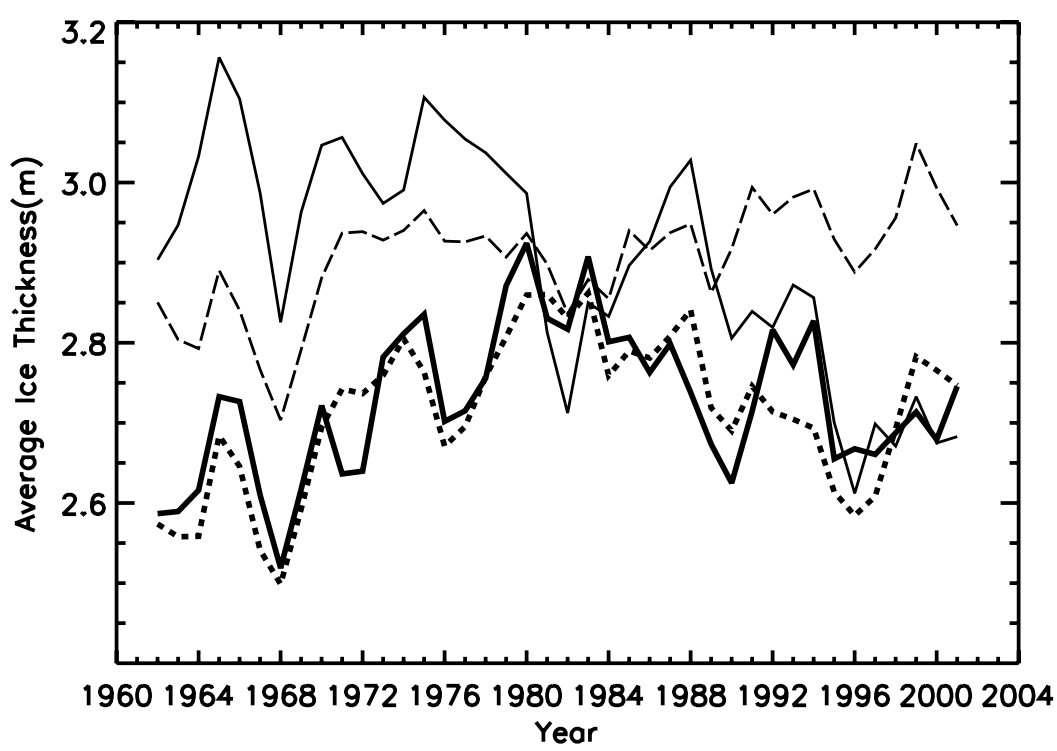

Figure 6. Arctic Basin sea ice thickness (m), as modeled by the ERA-40 (thick solid line) and NCEP (thin solid line) forced models, and by the ERA-40 (dotted line) and NCEP (dashed line) models with constant thermodynamic forcing between 1962 and 2001.

ice observational data sets after 1979 , we now examine the decadal changes in sea ice thickness between 1962 and 2001. Beginning with Figure 6, we plot the models' annualaveraged sea ice thickness (i.e., the annual- and areaaverage of the mean ice thickness in each grid cell, i.e., $h$ in equation (2) above) in the Arctic Basin. Overall, there are significant differences between the models' predictions, with the most significant occurring between 1962 and 1980, after which the agreement improves. The ERA-40 forced model predicts an increasing trend in annual mean thickness after 1962, reaching a maximum of approximately $2.9 \mathrm{~m}$ in 1980, and a slow decline from 1980 until 2001. The overall trend for the ERA-40 forced model is slightly positive at $0.2 \mathrm{~cm} /$ year, but since 1980 the ice thickness has declined at a rate of $0.85 \mathrm{~cm} /$ year, which is $3 \%$ of the mean per decade. By contrast, the NCEP forced model shows the Arctic Basin sea ice thickness to have been declining slowly since it reached a maximum of $3.15 \mathrm{~m}$ in 1966 . The overall trend is a decline of $0.9 \mathrm{~cm} /$ year, which is $3 \%$ of the mean per decade, but since 1980 the decline is more pronounced even than that predicted by the ERA- 40 forced model, at $1.1 \mathrm{~cm} /$ year, i.e., $4 \%$ of the mean per decade. The ice thickness time series of the two versions of the model are not highly correlated over the full 40 -year period $(R=0.09)$, but this rises to $R=0.51$ in the period since 1980 .

[20] In an effort to discern the causes of the modeled variability in annual mean thickness, we have forced the model since the beginning of 1962 with an annual climatology of each thermodynamic forcing set, so that the only annually varying forcing field is the 10-m wind (Figure 6), which is an approach that has been used in earlier studies [e.g., Köberle and Gerdes, 2003; Rothrock and Zhang, 2005]. Once again, there are considerable differences. The purely wind-forced variability in the ERA-40 forced model is highly correlated $(R=0.82)$ with the fully forced model. However, though this correlation is reduced $(R=0.70)$ after 1980 (indicating that the thermodynamic forcing plays a greater role in the model's interannual variability during that period of decreasing ice thickness), the decreasing trend is hardly changed.

[21] Conversely, the purely wind-forced ice thickness variability in the NCEP forced model is very different from the fully forced NCEP model's (they are negatively correlated, $R=-0.16$ ), with the previous decreasing trend becoming an increasing trend of over $1 \%$ of the mean per decade. This indicates that the thermodynamic forcing is the main cause of the decreasing sea ice thickness since 1966 in the NCEP forced model, which agrees with the findings of Rothrock and Zhang [2005], who used similar forcing to drive a coupled ice-ocean model run with a higher resolution. More specifically, since the snowfall, longwave and shortwave forcing are climatological means in the NCEP forced model, we can even trace the source of the negative trend further to the surface air temperature, $T_{\text {air }}$, and the specific humidity.

\subsection{Regional Predictions}

[22] To investigate regional ice thickness changes, we have divided the Arctic Basin into western and eastern regions divided by the Greenwich Meridian, and plot the results in Figure 7.

\subsubsection{Eastern Arctic Predictions}

[23] Immediately apparent in Figure 7 is the close agreement and high correlation $(R=0.72)$ between the models in the eastern region. Both models show a decreasing trend, though it is larger, at almost $6 \%$ of the mean per decade, for the NCEP forced model on account of its greater thickness ( 20-30 cm) there before 1980. After 1980, the models' eastern region thickness correlation rises to $R=0.87$.

[24] Comparing each model to its purely wind-forced version (not shown) reveals the wind forcing to be the main driver of interannual variability in this region, where the ERA-40 and NCEP forced models have correlations of $R=0.94$ and $R=0.77$ with their purely wind-forced versions, respectively. 


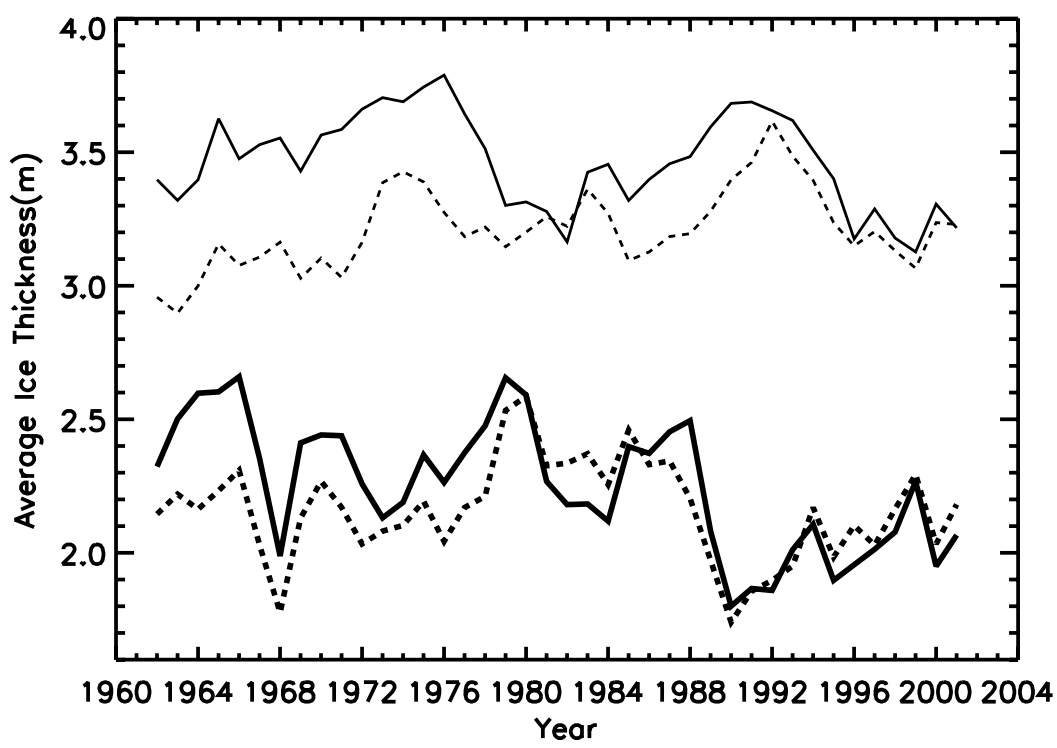

Figure 7. Sea ice thickness $(\mathrm{m})$ in the western (thin lines) and eastern (thick lines) Arctic Basin, as modeled by the ERA-40 (dotted line) and NCEP (solid line) models. We find that the interannual variability in the eastern region is primarily wind-driven.

\subsubsection{Western Arctic Predictions}

[25] Ice in the NCEP forced model is also considerably and consistently thicker than the ERA-40 forced model prior to 1980 in the western region. Once again, the correlation between models is not insignificant at $R=$ 0.48 , rising to $R=0.78$ after 1980 . However, the NCEP forced model shows a decreasing trend in this region over the full 40-year period which, when combined with the trend in the eastern region, contributes to the overall decreasing trend of $9 \mathrm{~cm} /$ decade. The ERA-40 forced model, on the other hand, exhibits an increasing trend here, which counteracts the decreasing trend in the eastern region to give the overall increasing trend of $2 \mathrm{~cm}$ per decade. Finally, there is also a high correlation between the ERA-40 forced model and its purely wind-forced version in the western region, at $R=0.90$ (not shown), but here the NCEP forced model is found to be more sensitive to thermodynamic forcing.

\section{Origins of Trends and Model Differences}

[26] Why do we see such different sea ice thicknesses and trends when the same model is forced by two different atmospheric forcing sets, particularly prior to 1979 ? It is clear that the differences in both model parameters and model forcing play a role here. However, we determined at the outset that we would compare both simulated time series of sea ice thickness subject to the constraint that they agree with the independent sets of sea ice observations used in the tuning process. Since different optimal parameters were arrived at depending on the forcing used, we see that differences in the forcing are fundamental to the sea ice thickness differences simulated.

\subsection{Influence of Optimal Parameter Choices}

[27] It is interesting to determine the extent to which the choice of optimal model parameters influence the trend in sea ice thickness over the full, 40-year simulation. We examine this in Figure 8, where we compare the sea ice thickness in the Arctic Basin as predicted by the NCEP forced model with that of the NCEP forced model using the same optimal parameter set as used in the ERA-40 forced model, namely $\left\{\alpha, C_{a}\right\}=\{0.62,0.00085\}$. We find that the reduction in these two parameter values neither changes the decreasing trend of $9 \mathrm{~cm}$ per decade, nor the simulated interannual variability, since the time series are highly correlated $(R=0.96)$. However, despite the trends and variability being largely unaffected by the parameter choices, we do see a large, $\approx 80 \mathrm{~cm}$ reduction in overall mean ice thickness, leading to poor agreement with satelliteand submarine-derived ice thicknesses and draft for this parameter choice with this forcing set.

[28] Though both versions of the model used the same altered yield curve shape determined by $e^{2}=0.5$ in the simulations described above, on account of the substantial improvements in the sea ice thickness spatial distribution it yields, there is also a danger that this could change both models' sea ice thicknesses trends and variability substantially. However, we do not find this to be the case. Figure 9 shows a comparison between the ERA-40 forced model and the same model with the standard [Hibler, 1979] value of $e^{2}=4$. Once more, though the overall ice thickness is decreased (by $\approx 25 \mathrm{~cm}$ ), both its 40 -year trend and the interannual variability $(R=0.93)$ are largely unchanged.

\subsection{Influence of Forcing Fields}

[29] Since we have seen that the parameter choices change neither the trends nor the interannual variability substantially, then the 40 -year sea ice thickness differences seen in comparing both versions of the model must be due to one or more of the applied forcing fields, which we now examine in turn.

\subsubsection{Radiative Forcing}

[30] As noted in section 2, Liu et al. [2005] showed the ERA-40 shortwave and longwave reanalysis fields are in closer agreement with SHEBA observations taken in $1997-$ 1998 [Perovich et al., 1999] than NCEP reanalysis fields. 


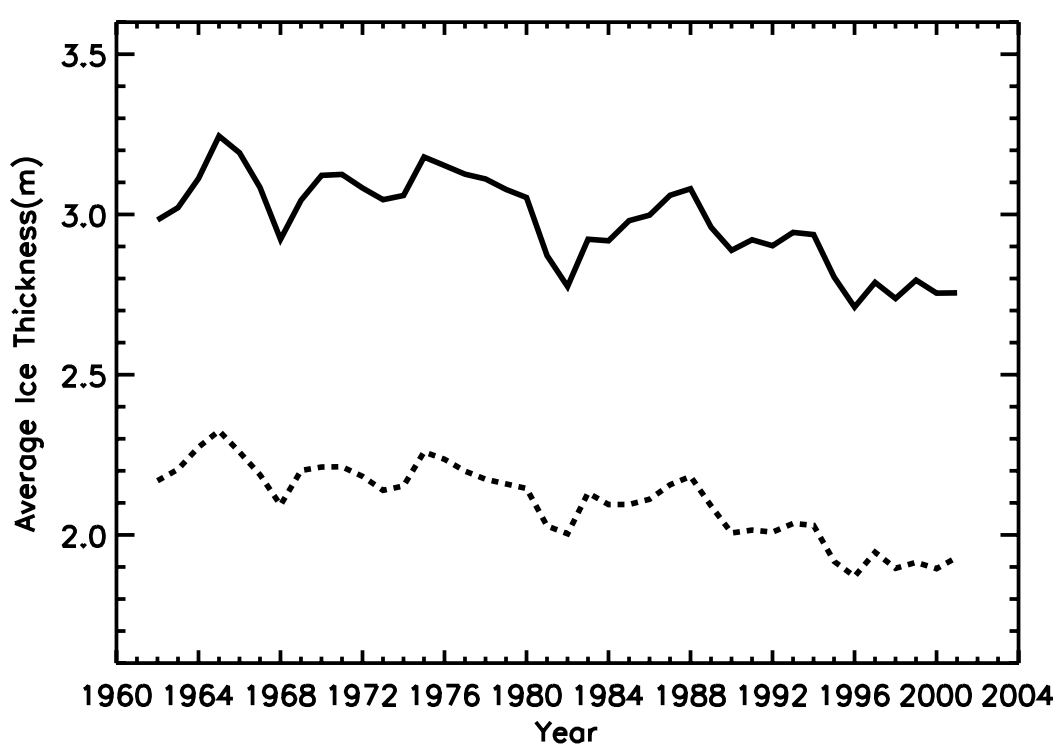

Figure 8. Arctic Basin sea ice thickness (m), as modeled by the NCEP forced model (solid line), and the NCEP model with the same optimal parameter set as used in the ERA-40 forced model (dotted line).

For this reason, we chose to replace the NCEP surface radiative fluxes with ERA-40 shortwave and longwave data, and chose to use a daily 1962-2001 climatology of these data to avoid introducing additional variability to influence the remaining NCEP forcing fields. We examine the effect of this change in Figure 10, where we compare the ERA-40 forced model with the same model, with the same parameters, but with both shortwave and longwave forcing replaced by the 1962-2001 climatology used to force the NCEP forced model. The overall change in ice thickness over the simulation period is a modest increase of $\approx 4 \mathrm{~cm}$, but the trend has changed from a slight increase of $0.2 \mathrm{~cm} /$ year to a slight decrease of $0.1 \mathrm{~cm} /$ year, or almost $10 \%$ of the annual decline seen in the NCEP forced model, a not insubstantial contribution to the trend.
[31] Since shortwave and longwave forcing are used directly in the thermodynamic heat balance, they can clearly influence the choice of optimal albedo parameter, $\alpha$. Increases in either or both during the summer, for example, would require a larger albedo to compensate for the extra energy at the surface. However, the radiative forcing used for both models is very similar in magnitude and is not the reason for the differing albedo values.

\subsubsection{Precipitation}

[32] Precipitation has a potentially large role to play in the mass balance of the Arctic sea ice, with snow's high albedo delaying the onset of summer sea ice melt and its insulating properties reducing ice growth in winter. Furthermore, its runoff freshens the mixed layer underneath the ice and contributes to the formation of melt ponds on the ice

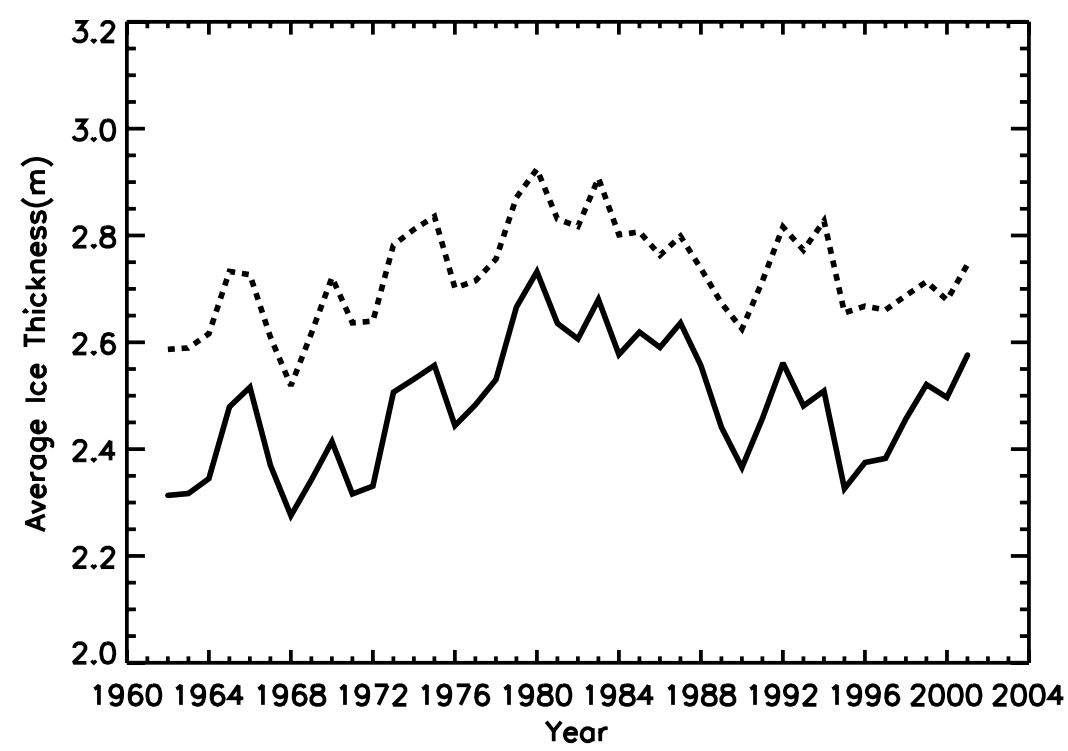

Figure 9. Arctic Basin sea ice thickness (m), as modeled by the ERA-40 forced model (dotted line), where the sea ice yield curve shape is determined by $e^{2}=0.5$, and the ERA-40 model with $e^{2}=4$ (solid line). 


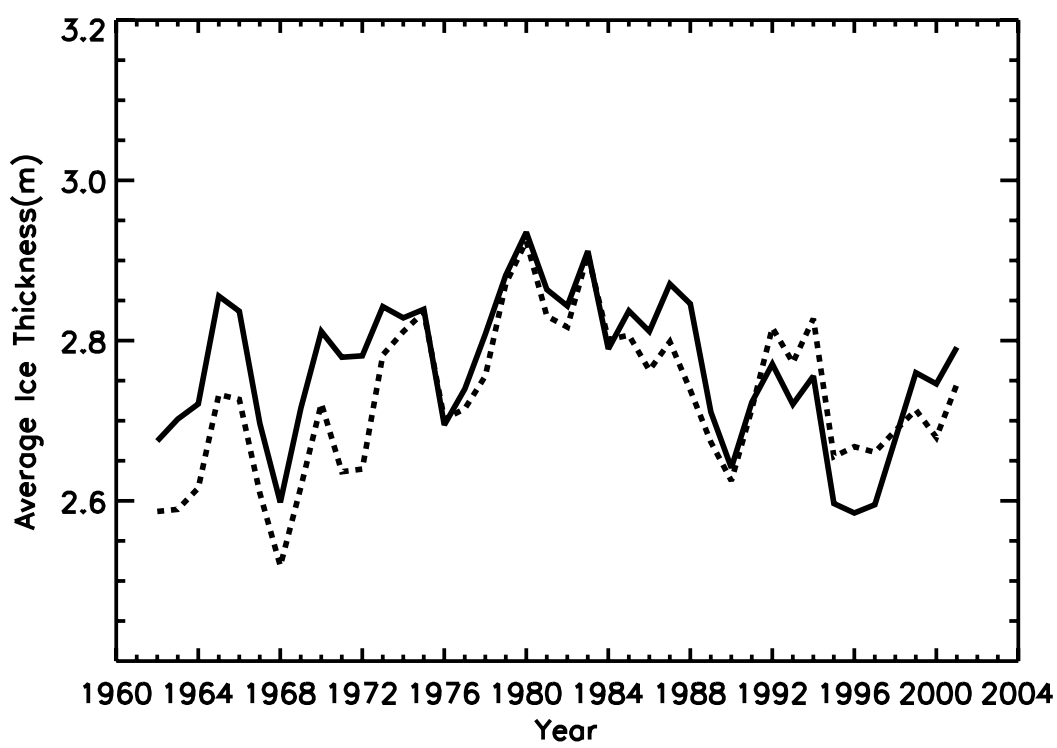

Figure 10. Arctic Basin sea ice thickness (m), as modeled by the ERA-40 forced model (dotted line), and the ERA-40 model with both shortwave and longwave forcing replaced by the climatology used to force the NCEP forced model (solid line).

surface, though neither process is treated explicitly in the version of CICE used here. Once more, we used for the NCEP-forced model a climatological precipitation, here taken from monthly-varying but regionally constant Vowinckel and Orvig [1970] data, as also used by Zhang et al. [1998a]. We plot the annual- and area-averaged snowfall rate in Figure 11 (solid line), and find no substantial trends, the variability being introduced by the fact that modeled snowfall is treated as rain, and immediately allowed to run off, when $T_{\text {air }}$ exceeds $0^{\circ} \mathrm{C}$.

[33] The ERA-40 snowfall rate is higher on average owing to greater snowfall in April, May, September and October (not shown), but it has only a slight overall decreasing trend caused by a small decline in snowfall during the winter months (November to March) that outweighs an even smaller increase during the summer months. Replacing the precipitation climatology used in the NCEP model with the variable ERA-40 snowfall decreases the overall ice thickness slightly (not shown) since the greater snowfall during September and October reduces winter ice growth. This also changes the ice thickness decline slightly from $0.9 \mathrm{~cm} /$ year to $0.75 \mathrm{~cm} /$ year. However, the interannual variability is largely unchanged $(R=0.96)$.

\subsubsection{Wind Forcing}

[34] Differences in $10 \mathrm{~m}$ wind forcing have the potential to greatly influence the simulated sea ice variability, since the air stress as calculated in equation (1) scales quadratically with wind speed. We plot the annual-average zonal,

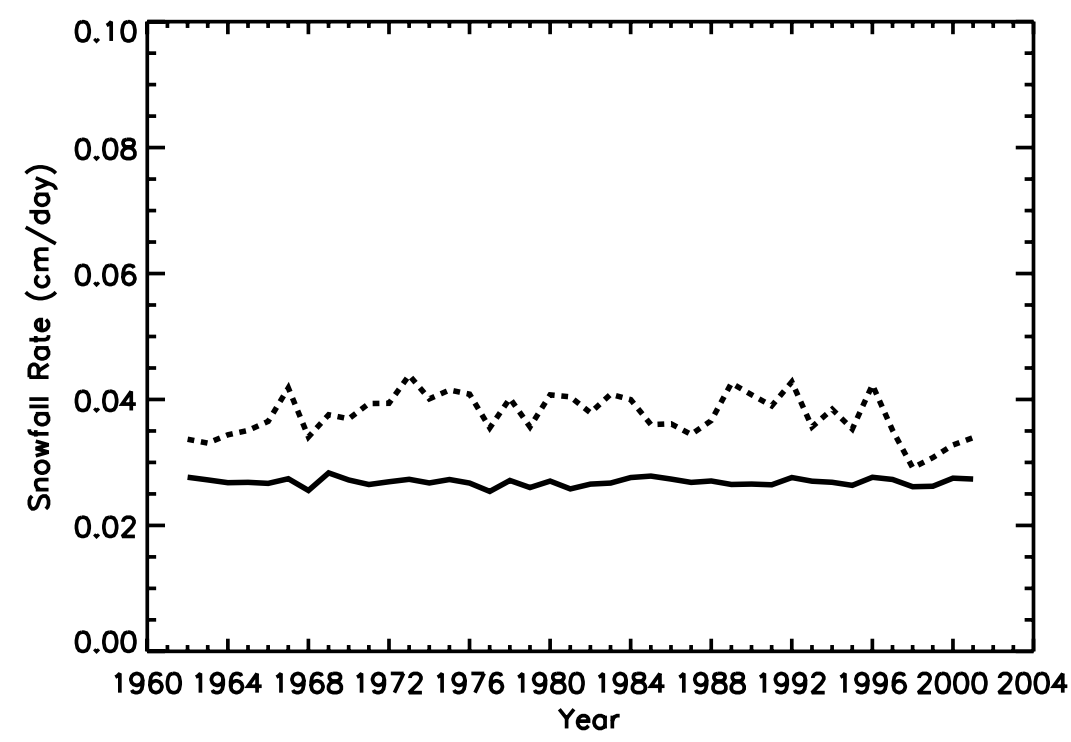

Figure 11. Annual-averaged snowfall $\left(\mathrm{cm} \mathrm{d}^{-1}\right)$ used to force the ERA-40 (dotted line) and NCEP (solid line) models. 


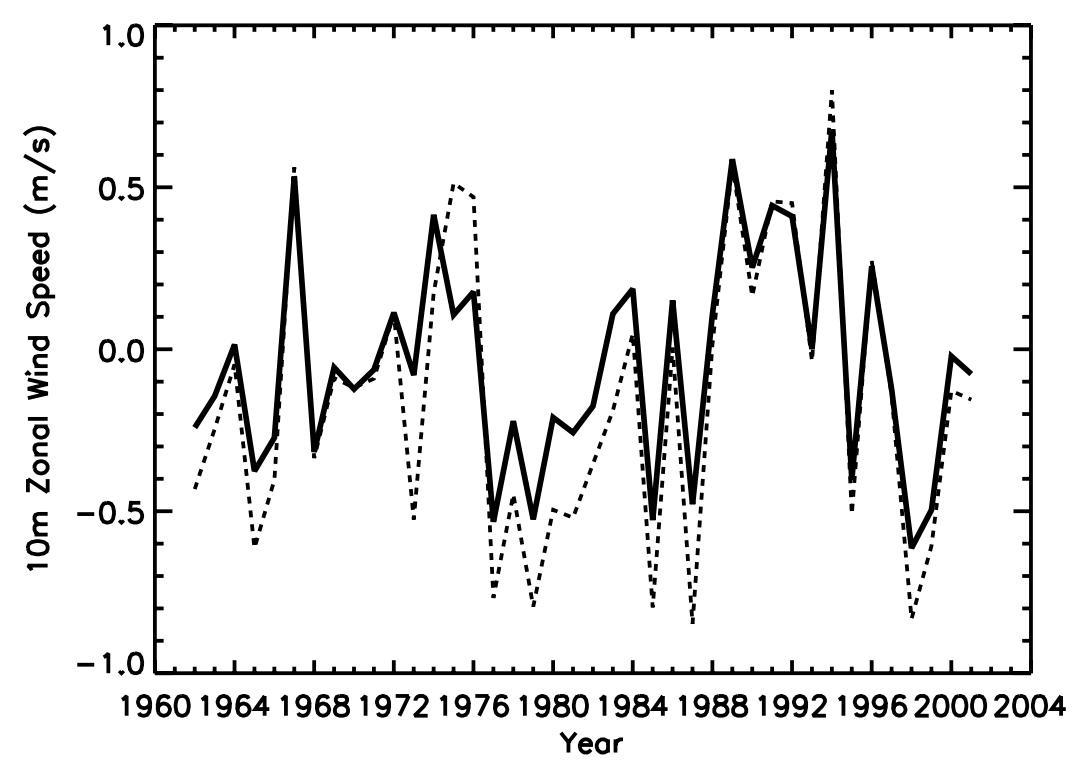

Figure 12. Annual average zonal 10-m wind speed $\left(\mathrm{m} \mathrm{s}^{-1}\right)$ in the Arctic Basin, as given by the ERA-40 reanalysis (dotted line), and the NCEP reanalysis (solid line).

meridional, and absolute speeds in Figures 12, 13, and 14, respectively, as given by the ERA-40 (dotted lines) and NCEP (solid lines) reanalyses. Immediately apparent is their high correlation, at $R=0.95$ (zonal), $R=0.92$ (meridional), and $R=0.89$ (absolute), presumably due to the use of the same pressure fields in the reanalysis. However, we also note that the NCEP $10 \mathrm{~m}$ winds are generally weaker than those of the ERA-40 reanalysis (see Figure 14), which may be one reason why the optimal air drag parameter choice in the NCEP forced model $\left(C_{a}=0.00135\right)$ was higher than the value chosen in the ERA-40 forced model.

[35] As discussed in section 4, both versions of the model exhibit very different behavior when the sole interannually variable forcing is the $10 \mathrm{~m}$ wind field. It is crucial, therefore, to know the degree to which the reanalysis fields reflect observed fields. Bromwich and Wang [2005] have compared the two reanalysis wind data sets to independent rawinsonde data taken during the CEAREX and LeadEx field experiments during the late 1980s and early 1990s. They found that, at all pressure levels above the surface pressure level $(1000 \mathrm{hPa})$, both reanalysis data sets capture the observed variability well, that there are biases in magnitudes, but that, on average, ERA-40 had the highest correlations and lowest biases. Agreement is less good near the surface pressure level, but NCEP winds were found to have had more negative wind speed biases there [Bromwich and Wang, 2005, Tables 1 and 2]. Similarly, Curry et al. [2002] compared $10 \mathrm{~m}$ wind speeds as observed during the SHEBA field experiment to the predictions of the NCEP reanalysis (as well as the ECMWF's precursor to the ERA-40

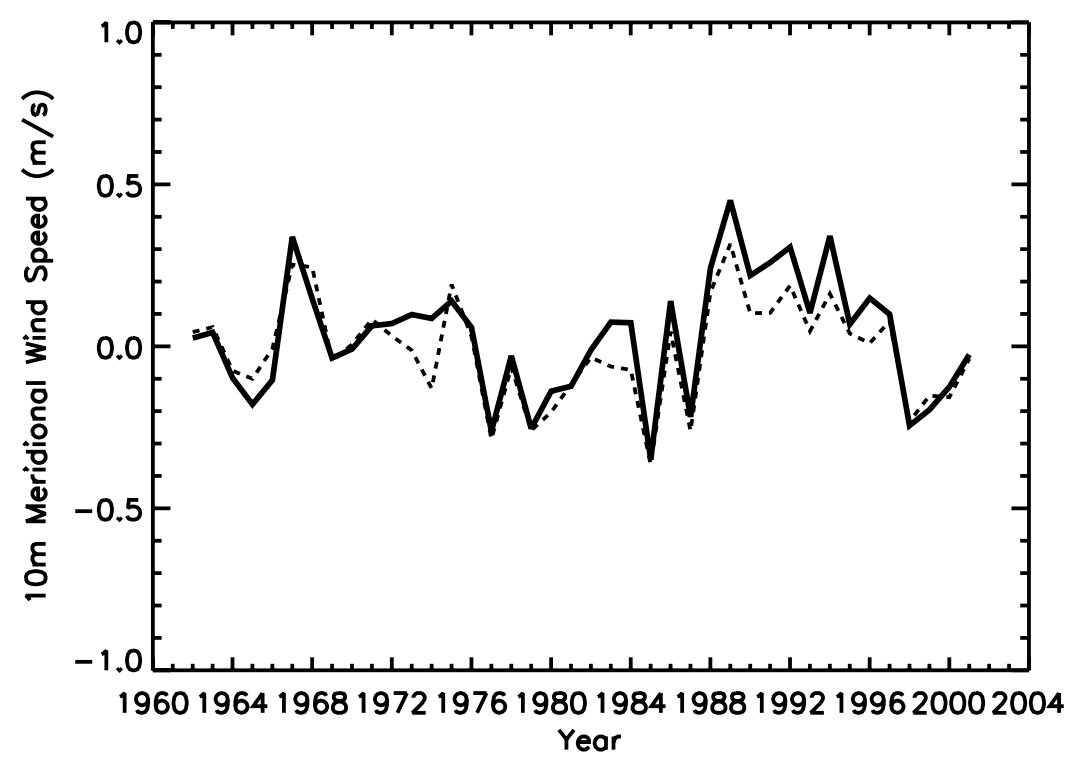

Figure 13. Annual average meridional $10-\mathrm{m}$ wind speed $\left(\mathrm{m} \mathrm{s}^{-1}\right)$ in the Arctic Basin, as given by the ERA-40 reanalysis (dotted line), and the NCEP reanalysis (solid line). 


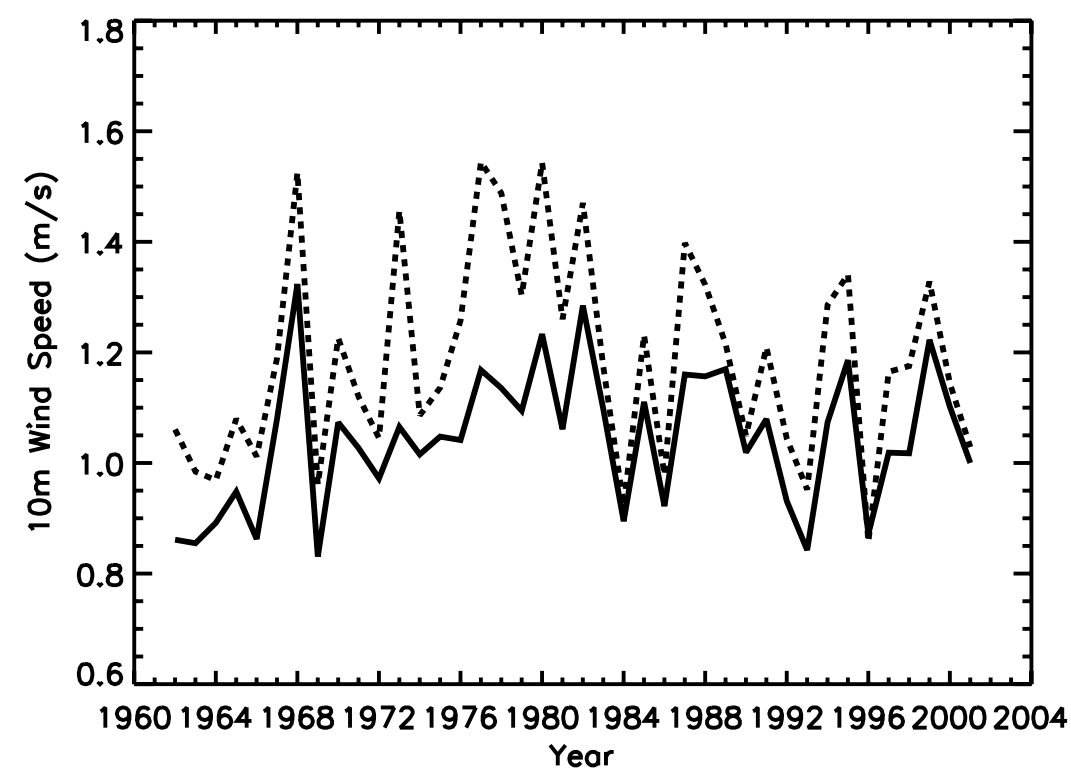

Figure 14. Annual average 10-m wind speed $\left(\mathrm{m} \mathrm{s}^{-1}\right)$ in the Arctic Basin, as given by the ERA-40 reanalysis (dotted line), and the NCEP reanalysis (solid line).

reanalysis, ERA-15), and they too found that the NCEP winds were weaker than those observed [Curry et al., 2002, Table 2].

\subsubsection{Surface Temperature}

[36] Surface air temperature is of crucial importance to, and a reflection of, the seasonal evolution of Arctic sea ice, varying from $\approx-35^{\circ} \mathrm{C}$ in midwinter to near freezing point over ice in summer. It arises in the sea ice thermodynamic heat balance (evaluated separately for each ice thickness category) directly in the simple bulk parameterization of the sensible heat flux [Miller et al., 2006],

$$
F_{\text {sens }}=\rho_{a} c_{m a}\left(\left|\mathbf{u}_{\mathbf{a}}\right| C_{s}+1\right)\left(T_{\text {air }}-T_{s f c}\right),
$$

where $\rho_{a}$ is the density of air, $c_{m a}$ is the specific heat of moist air, $C_{s}$ is the exchange coefficient $=0.002, T_{s f c}$ is the surface temperature for an ice thickness category, and all heat fluxes are positive downward. (This parameterization also takes into account sensible heat transfer in windless conditions with $\mathbf{u}_{\mathbf{a}}=0$ [Jordan et al., 1999].)

[37] A comparison of the temporal evolution of annually averaged $T_{\text {air }}$ for the two forcing sets in Figure 15 reveals some striking differences. Though the two time series are highly correlated $(R=0.89)$, the NCEP $T_{\text {air }}$ is considerably lower than the ERA-40 value, mainly on account of lower temperatures during the polar winter, October to March (not shown). The annual trends are different, at $\approx 0.54^{\circ} \mathrm{C}$ per decade in the NCEP data set, and $\approx 0.23^{\circ} \mathrm{C}$ per decade in the

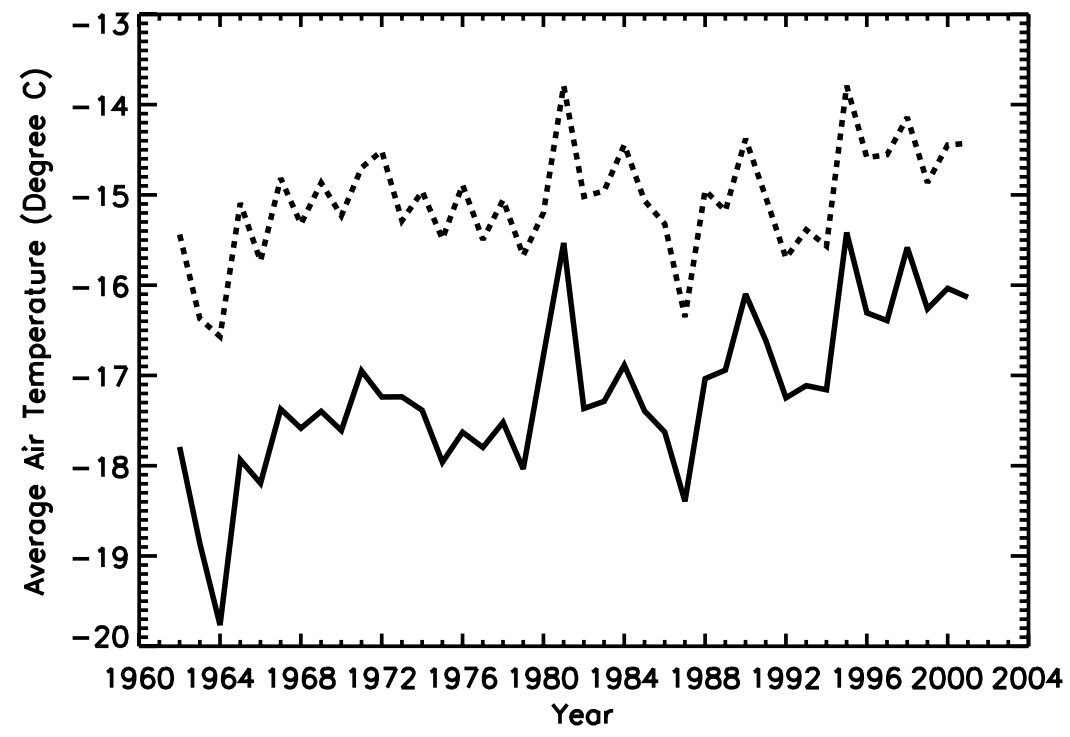

Figure 15. Annual average air temperature, $T_{\text {air }},\left({ }^{\circ} \mathrm{C}\right)$ in the Arctic Basin, as given by the ERA-40 reanalysis (dotted line), and the NCEP reanalysis (solid line). 


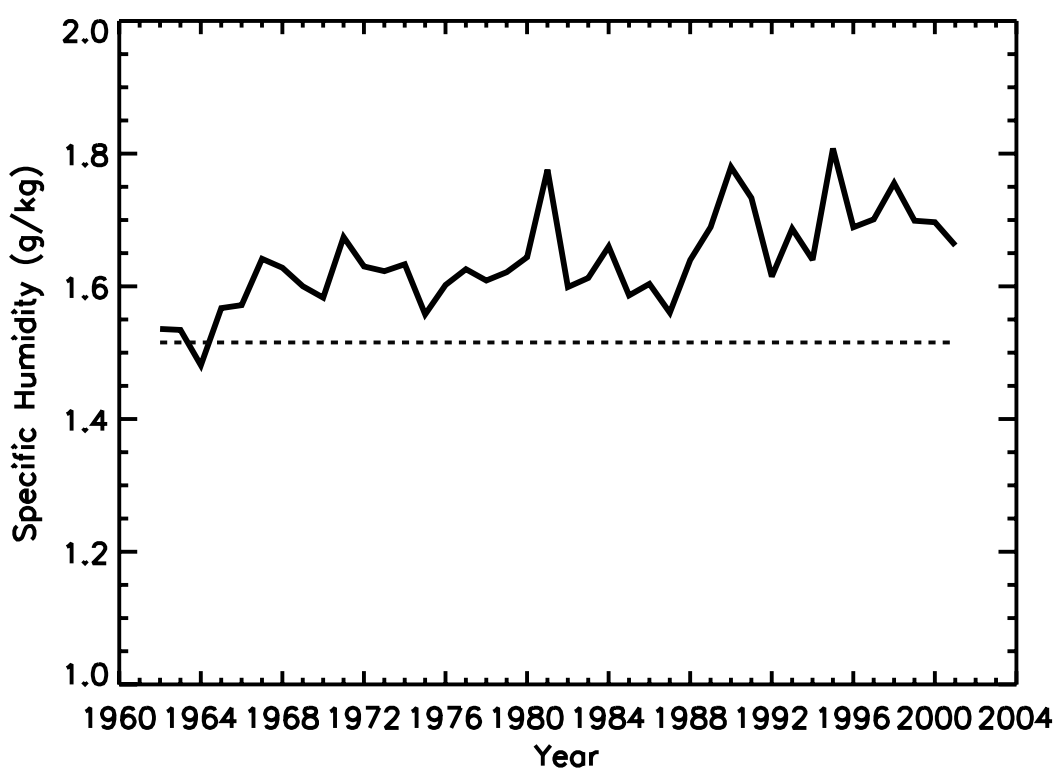

Figure 16. Annual average specific humidity $\left(\mathrm{g} \mathrm{kg}^{-1}\right)$ in the Arctic Basin, as given by the POLES climatology used in the ERA-40 forced model (dotted line), and the NCEP reanalysis (solid line).

ERA-40 set. The monthly and seasonal temperature trends also differ. Both data sets show the greatest increases from February to May, and from September to November, but the NCEP temperatures increase at almost twice the rate of the ERA-40 values (not shown). Our imposition of an upper $T_{\text {air }}$ limit of $273.65 \mathrm{~K}$ whenever the ice concentration in a grid cell exceeded 0.15 [Flato, 1995] reduces the applied temperature variability, especially for the ERA-40 forced model, but is a reasonable correction of the reanalysis forcing.

[38] The increasing temperatures also lead to an increase in the downward $F_{\text {sens }}$ for all months in the NCEP forced model, and in all months apart from August in the ERA-40 forced model (not shown). This direct effect on the surface heat balance would lead to thinner ice if it were the only change occurring.

[39] Bromwich and Wang [2005] also noted differences when comparing ERA-40 and NCEP data to surface temperature observations taken during the CEAREX campaign. During winter, the NCEP data had a negative bias of $2-3^{\circ} \mathrm{C}$, whereas ERA-40 had a positive bias of approximately the same magnitude [Bromwich and Wang, 2005, Figure 5a]. However, they note that ERA-40 displayed the best skill in capturing observations overall. Similarly, Curry et al. [2002] found negative biases in NCEP winter temperatures by comparison with SHEBA observations.

[40] It is interesting to note here that different surface air temperature forcing can influence the choice of optimal parameters, as mentioned in section 3.1. If $T_{\text {air }}$ is increased, then according to equation (3) we would expect a greater downward (or less negative upward) $F_{\text {sens. }}$. If this increase occurs during a period when the downward shortwave radiation is greater than zero, we might require a larger albedo, $\alpha$, to compensate for the extra energy at the surface. Indeed, this is what we find, since NCEP temperatures are generally greater than ERA-40 values, and the larger albedo value needed may partly have been to compensate for this.

[41] Finally, we note that the lower air temperatures seen in the NCEP data could strongly reinforce the trend toward thicker ice when the North Atlantic Oscillation (NAO) index is low, as it mostly was between 1960 and 1980 [Rothrock et al., 2003], to give the larger sea ice thickness differences in that period.

\subsubsection{Specific Humidity}

[42] Like $T_{\text {air }}$ above, the surface specific humidity, $Q_{\text {air }}$, arises in the sea ice thermodynamic heat balance directly in the simple bulk parameterization of the latent heat flux [Miller et al., 2006],

$$
F_{\text {lat }}=\rho_{a} L_{\text {sub }}\left|\mathbf{u}_{\mathbf{a}}\right| C_{s}\left(Q_{a i r}-Q_{s f c}\right),
$$

where $L_{s u b}$ is the latent heat of sublimation of fresh water, and $Q_{s f c}$ is the surface saturation specific humidity for the ice thickness category (and an increasing function of $T_{s f c}$ ).

[43] As discussed in section 4, the negative trend in sea ice thickness in the NCEP forced model can be traced to some combination of $T_{\text {air }}$ and specific humidity forcing. The ERA-40 forced model, however, has climatological specific humidity forcing derived from the POLES sea ice model forcing set. We plot the annual average specific humidity for both versions of the model in Figure 16, and the 1962-2001 daily climatological forcing in Figure 17. Figure 17 confirms that the greater annual average humidity seen in the NCEP forced model after 1964 is due to NCEP's greater summer humidity, and even a slightly shifted seasonality, relative to the POLES humidity forcing. We also note a pronounced increasing trend in the NCEP forcing in Figure 16.

[44] Just as with surface air temperature forcing, higher $Q_{\text {air }}$ values, especially in summer, can require a higher albedo, $\alpha$, to compensate for the extra latent heat directed into or remaining at the surface. Could this increasing humidity trend have contributed substantially to the decreasing sea ice thickness trend in the NCEP forced model? To investigate this possibility, we performed two sensitivity experiments. In the first, we held the specific humidity constant after 1962 in the NCEP forced model and 


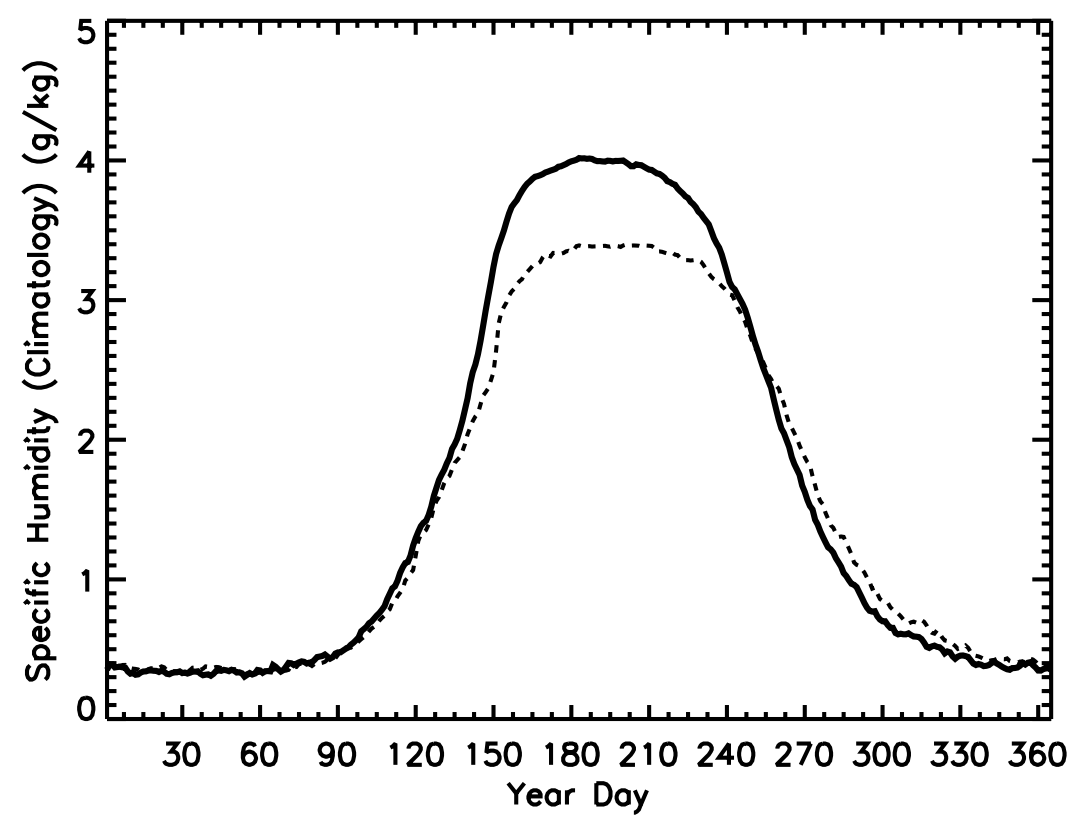

Figure 17. Specific humidity $\left(\mathrm{g} \mathrm{kg}^{-1}\right)$ climatology $(1962-2001)$ in the Arctic Basin, as given by the POLES data set used in the ERA-40 forced model (dotted line), and the NCEP reanalysis (solid line).

compared the simulated thicknesses in Figure 18. Holding the specific humidity constant reduces the decreasing thickness trend to $0.36 \mathrm{~cm} /$ year from $0.9 \mathrm{~cm} /$ year. This is mainly due to the decreasing trend in $F_{\text {lat }}$ (not shown) that results when $Q_{\text {air }}$ is held constant at its low 1962 values and the surface temperature $T_{s f c}$ (and thus $Q_{s f c}$ ) is allowed to increase owing to the larger downward $F_{\text {sens }}$ as $T_{\text {air }}$ rises, see equations (3) and (4). Thus the constant specific humidity partly reduces the effect of the increasing temperatures.

[45] We see a similar effect in the second experiment, where we replaced the POLES humidity forcing in the ERA-40 model with the NCEP humidity field and plot the results in Figure 19. In addition to the large drop in mean ice thickness (we did not recalibrate against the observations, so the albedo was too low), we note that the slightly positive trend seen in the ERA-40 model has now become a decreasing trend of $0.36 \mathrm{~cm} /$ year, which is $40 \%$ of the $0.9 \mathrm{~cm} /$ year decreasing trend seen in the NCEP forced model. This new trend is a result of the same physics seen in the first experiment: we get more positive latent heat fluxes when $Q_{\text {air }}$ is allowed to increase, which, when combined with a larger downward $F_{\text {sens }}$ as $T_{\text {air }}$ rises (equations (3) and (4)), gives increased melt and thinner ice.

[46] Furthermore, the correlation between the annual ice thickness predicted by the NCEP forced model and this ERA-40 model with the NCEP humidity field, previously a

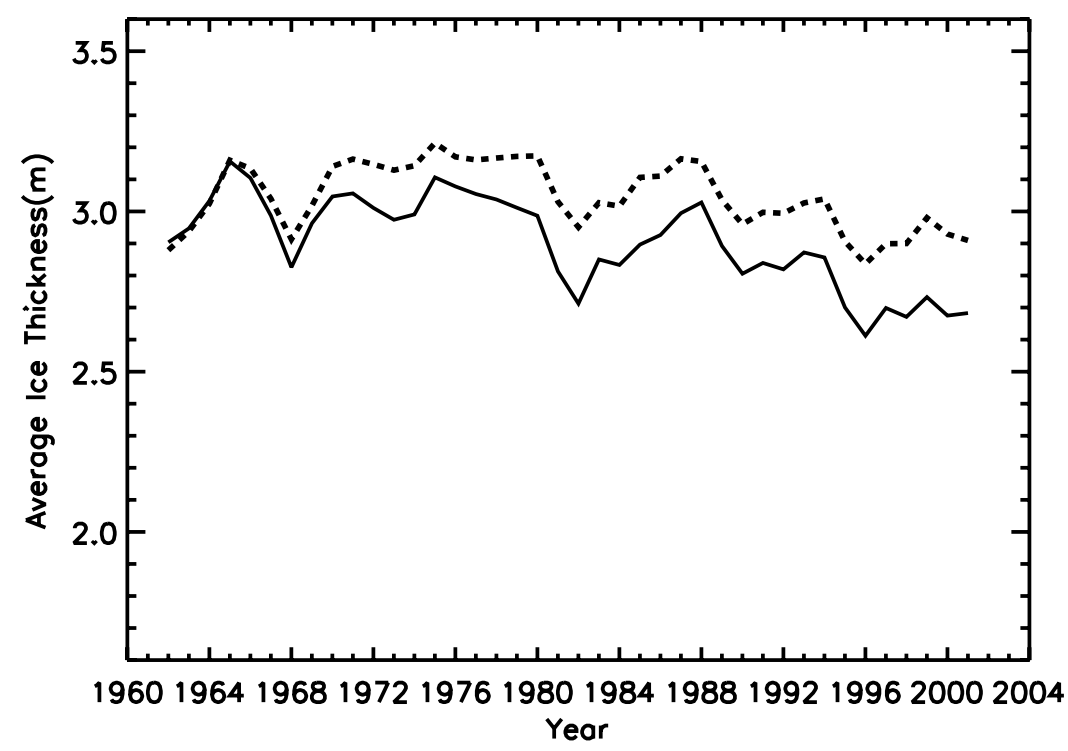

Figure 18. Arctic Basin sea ice thickness (m), as modeled by the NCEP forced model (solid line), and the NCEP model with specific humidity forcing held constant after 1962 (dotted line). 


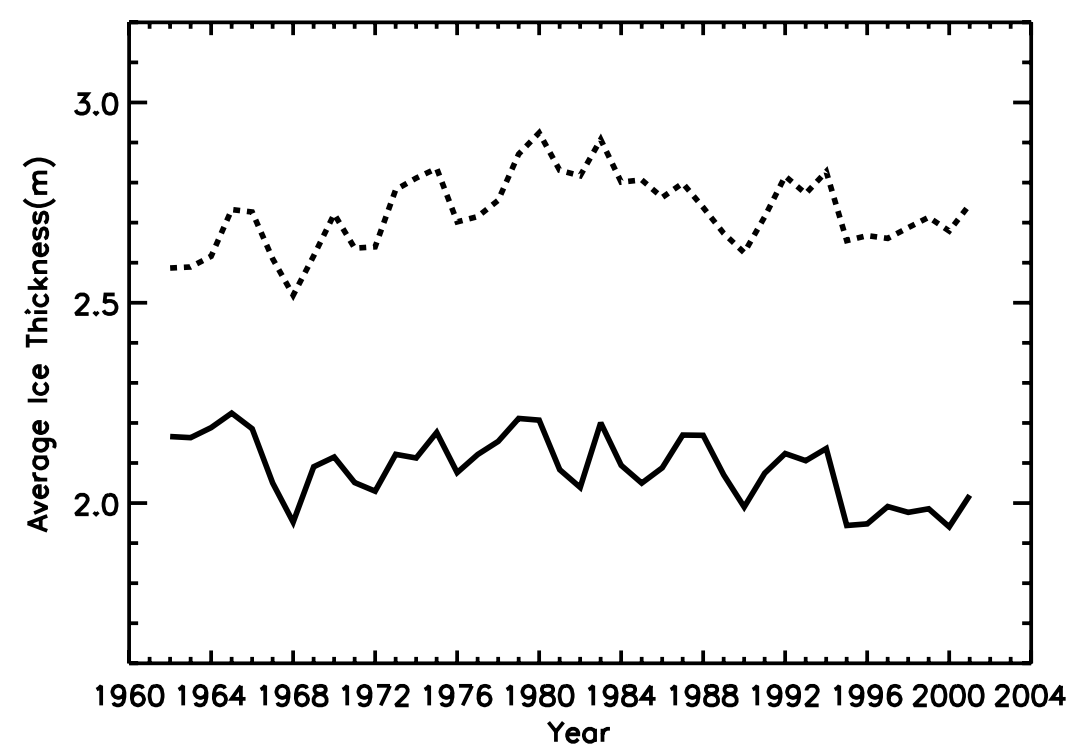

Figure 19. Arctic Basin sea ice thickness (m), as modeled by the ERA-40 forced model (dotted line), and the ERA-40 model with specific humidity forcing replaced by the values from the NCEP forced model (solid line).

low $R=0.1$ between the original versions' ice thickness time series, now rises to $R=0.74$, which demonstrates that the specific humidity contributes substantially to the variability seen in the NCEP forced model.

[47] In a similar study of decadal Arctic sea ice volume changes, Hilmer and Lemke [2000] used a dynamicthermodynamic sea ice model with the only annually varying forcing fields being NCEP $10 \mathrm{~m}$ winds and $T_{\text {air }}$, that is with specific humidity, cloud coverage and precipitation being fixed annual cycles. However, they also found a substantial decreasing trend in sea ice volume, $-4 \%$ per decade, between 1961 and 1998, despite this reduced variability in applied NCEP forcing.

[48] There are few direct validations of NCEP and POLES specific humidity fields. However, Curry et al. [2002] have used year-long SHEBA data to demonstrate that NCEP was consistently better in seasonal comparisons, with smaller biases and better correlations than POLES data. In the important summer months between April and September, however, when specific humidity influences the surface heat balance through its influence on latent heat flux, NCEP had a positive bias of $0.2 \mathrm{~g} \mathrm{~kg}^{-1}$ on average, whereas the POLES data had near zero bias on average [Curry et al., 2002, Table 2].

\section{Discussion and Conclusions}

[49] The CICE model has been forced with two different reanalysis data sets, tuned independently, and used to generate 40-year predictions of sea ice thickness in the central Arctic. Both versions of the model, upon tuning a limited set of parameters, show some skill in reproducing observed properties of sea ice since 1979, during which period the models' predictions also agree more closely. Since CICE includes many of the recent advances in sea ice modeling [Hunke and Lipscomb, 2001] now found in the GCMs used in the IPCC's AR4 [Zhang and Walsh, 2006], this ought to increase confidence in the representation of the Arctic sea ice processes in these models.

[50] In general, we find that we can divide this 40-year period of comparison into two distinct periods. During the first period, from 1962 to 1978, substantial disagreement in thickness and trends, though not necessarily variability, was found between the models, especially in the western Arctic Ocean, highlighting the significant influence that forcing fields can have on the interpretation of sea ice model predictions. Unfortunately, there are few observational data sets available prior to 1979 , so it is difficult to validate sea ice models over the full period of sea ice draft decline reported by Rothrock et al. [1999]. It would certainly be helpful to be able to use the ULS data from early submarine cruises, though it is known that data recorded on paper charts before 1976 have a bias toward thicker ice [Wensnahan and Rothrock, 2005].

[51] Better agreement in thickness, variability and trends is seen in the second period from 1979 to 2001. This could partly be a consequence of the fact that all the observations used to tune the model parameters were made after 1979. However, it may also be due to the fact that the volume of data used in the production of the ERA-40 and NCEP reanalyses also increased after 1979, when both data from the International Arctic Buoy Programme and satellite measurements of sea ice concentration became available. This surely contributed to an improvement in the quality of the reanalyses in the polar regions, and consequently more consistency between the fields used to force sea ice models such as CICE. The improved agreement seen in this most recent period is also consistent with the analysis of Rothrock et al. [2003], who revealed large differences in the thickness predictions of 8 different sea ice models in the Arctic, but an increased consistency after 1980 [Rothrock et al., 2003, Figure 12].

[52] In addition to both versions of the model demonstrating some skill in reproducing observations, there are a 
number of consistent features that emerge from the 40-year sea ice thickness comparison. Most striking in the results presented here, and in other studies [e.g., Rothrock et al., 2003], is the steady decline in Arctic sea ice thickness since 1980 , which at $3-4 \%$ of the mean per decade is comparable to the decline seen in observations of sea ice extent [Parkinson and Cavalieri, 2002]. If this thickness trend continues, as seems to be the case with sea ice extent [Stroeve et al., 2005], we could witness dramatic changes to the Arctic in the coming century [Arctic Climate Impact Assessment, 2004; Zhang and Walsh, 2006].

[53] The decline in the sea ice thickness seen in the Eastern Arctic is also a robust feature, with both versions of the model showing a decline over the 40-year period of analysis (see Figure 7), which accelerates after 1980, with a particularly large decline in the late 1980s. Comparisons with purely wind forced versions of the model reveal the variability seen in the Eastern Arctic to be a result of wind forcing.

[54] Different optimal parameter choices were needed to maintain agreement with observations when forcing was changed. Some possible reasons for the differences are given in section 5 . However, this did not substantially affect the simulated 40-year thickness variability and trends. Rather, we find that differences are mostly due to differences in the forcing fields used, and in how they are used, for example through the use of a climatological or an interannually variable forcing field.

[55] There are only slight differences in the radiative fields applied to force the models and precipitation forcing has a small effect on the observed decadal trends, but not the variability. NCEP and ERA-40 winds are strongly correlated, but NCEP's weaker winds are believed to be one reason for the need to have higher air drag coefficient in the tuning of the NCEP forced model. Large differences are found in the magnitude and trend of the Arctic Basin temperature forcing, however, though the interannual variability is highly correlated. Indeed, temperature, through its direct effect on $F_{\text {sens }}$, is one forcing field responsible for the large ice thickness decline seen in the NCEP forced model, though comparisons with observations reveal it to have a cold bias in winter. The other is specific humidity, which, when used to replace the POLES climatology in the otherwise ERA-40 forced model, changes the slightly increasing trend there to a decreasing thickness trend that is $40 \%$ of the decreasing trend seen in the NCEP forced model. This was due to the increase in $F_{\text {lat }}$ with $Q_{\text {air }}$, which, when combined with an increasing $F_{\text {sens }}$, can lead to a reduction in sea ice thickness. Holding $Q_{\text {air }}$ constant resulted in an increasing trend in upward $F_{\text {lat }}$ that can offset the downward $F_{\text {sens }}$. This reduces the thermodynamic sensitivity of the model, as seen in Figure 6.

[56] Since it is more likely that errors exist in the earlier periods of the reanalysis forcing data when data assimilation was sparse, as discussed by Bromwich and Fogt [2004] for the case of the Southern Hemisphere, and since these errors can influence the modeled trends, we see that uncertainty, differences and errors in sea ice model forcing sets complicate the use of models to determine the exact causes of the recently reported decline in Arctic sea ice thickness. However, reanalysis data can help in the determination of robust features if the models are tuned appropriately against observations.

[57] Acknowledgments. We thank the developers of CICE for making it freely available to the scientific community, the European Space Agency for the provision of the ERS data, the NSIDC for providing sea ice concentration, draft, and velocity data, and the IABP/POLES teams for providing additional forcing data. ERA-40 reanalysis data were provided by the ECMWF (http://www.ecmwf.int/research/era/) through the British Atmospheric Data Centre (http://badc.nerc.ac.uk). NCEP/NCAR reanalysis data were provided through the NOAA Climate Diagnostics Center (http:/ www.cdc.noaa.gov). We also thank two anonymous reviewers for their constructive remarks on an earlier version of this work. P. M. was funded by NERC through the Centre for Polar Observation and Modelling.

\section{References}

Arctic Climate Impact Assessment (2004), Arctic Climate Impact Assessment: Scientific Report, 144 pp., Cambridge Univ. Press, New York.

Bitz, C. M., and W. H. Lipscomb (1999), An energy-conserving thermodynamic sea ice model for climate study, J. Geophys. Res., 104, 15,66915,677 .

Bromwich, D. H., and R. L. Fogt (2004), Strong trends in the skill of the ERA-40 and NCEP-NCAR reanalyses in the high and midlatitudes of the Southern Hemisphere, 1958-2001, J. Clim., 17(23), 4603-4619.

Bromwich, D. H., and S.-H. Wang (2005), Evaluation of the NCEP-NCAR and ECMWF 15- and 40-Yr reanalyses using rawinsonde data from two independent Arctic field experiments, Mon. Weather Rev., 133, 35623578.

Cavalieri, D. J., C. L. Parkinson, P. Gloersen, and H. J. Zwally (2002), Sea ice concentrations from Nimbus-7 SMMR and DMSP SSM/I passive microwave data [CD-ROM], Natl. Snow and Ice Data Cent., Boulder, Colo.

Comiso, J. C. (2002), A rapidly declining perennial sea ice cover in the Arctic, Geophys. Res. Lett., 29(20), 1956, doi:10.1029/2002GL015650.

Curry, J. A., J. L. Schramm, A. Alam, R. Reeder, T. E. Arbetter, and P. Guest (2002), Evaluation of data sets used to force sea ice models in the Arctic Ocean, J. Geophys. Res., 107(C10), 8027, doi:10.1029/2000JC000466.

Flato, G. M. (1995), Spatial and temporal variability of Arctic ice thickness, Ann. Glaciol., 21, 323-329.

Fowler, C. (2003), Polar Pathfinder daily $25 \mathrm{~km}$ EASE-grid sea ice motion vectors, http://nsidc.org/data/nsidc-0116.html, Natl. Snow and Ice Data Cent., Boulder, Colo.

Hibler, W. D., III (1979), A dynamic-thermodynamic sea ice model, J. Phys. Oceanogr., 9, 815-846.

Hibler, W. D., III, and K. Bryan (1984), Ocean circulation: Its effects on seasonal sea-ice simulations, Science, 224, 489-492.

Hilmer, M., and P. Lemke (2000), On the decrease of Arctic sea ice volume, Geophys. Res. Lett., 27, 3751-3754.

Hunke, E. C., and J. K. Dukowicz (1997), An elastic-viscous-plastic model for sea ice dynamics, J. Phys. Oceanogr., 27, 1849-1867.

Hunke, E. C., and J. K. Dukowicz (2002), The elastic-viscous-plastic sea ice dynamics model in generalized orthogonal curvilinear coordinates on a sphere-Incorporation of metric terms, Mon. Weather Rev., 130, 18481865.

Hunke, E. C., and W. H. Lipscomb (2001), CICE: The Los Alamos Sea Ice Model, documentation and software user's manual, version 3, LACC-9816, Los Alamos Natl. Lab., Los Alamos, N. M. (Available at http:/ climate.lanl.gov/Models/CICE/index.htm)

Jordan, R. E., E. L. Andreas, and A. P. Makshtas (1999), Heat budget of snow-covered sea ice at North Pole 4, J. Geophys. Res., 104, 7785-7806.

Kalnay, E., et al. (1996), The NCEP/NCAR 40-year reanalysis project, Bull. Am. Meteorol. Soc., 77(3), 437-470.

Köberle, C., and R. Gerdes (2003), Mechanisms determining the variability of Arctic sea ice conditions and export, J. Clim., 16, 2843-2858.

Laxon, S., N. Peacock, and D. Smith (2003), High interannual variability of sea ice thickness in the Arctic region, Nature, 425, 947-950.

Lindsay, R. W., and J. Zhang (2005), The thinning of Arctic sea ice, 19882003: Have we passed a tipping point?, J. Clim., 18, 4879-4894.

Liu, J., J. A. Curry, W. B. Rossow, J. R. Key, and X. Wang (2005), Comparison of the surface radiative flux data sets over the Arctic Ocean, J. Geophys. Res., 110, C02015, doi:10.1029/2004JC002381.

Miller, P. A., S. W. Laxon, and D. L. Feltham (2005), Improving the spatial distribution of modeled Arctic sea ice thickness, Geophys. Res. Lett., 32, L18503, doi:10.1029/2005GL023622.

Miller, P. A., S. W. Laxon, D. L. Feltham, and D. J. Cresswell (2006), Optimization of a sea ice model using basin-wide observations of Arctic sea ice thickness, extent and velocity, J. Clim., 19, 1089-1108. 
Parkinson, C. L., and D. J. Cavalieri (2002), A 21 year record of Arctic seaice extents, and their regional, seasonal and monthly variability and trends, Ann. Glaciol., 34, 441-446.

Parkinson, C. L., and W. M. Washington (1979), A large-scale numerical model of sea ice, J. Geophys. Res., 84, 311-337.

Perovich, D. K., et al. (1999), Year on ice gives climate insights, Eos Trans $A G U, 80(41), 481,485-486$.

Rigor, I. G., R. L. Colony, and S. Martin (2000), Variations in surface air temperature observations in the Arctic 1979-97, J. Clim., 13, 896-914

Rothrock, D. A., and J. Zhang (2005), Arctic Ocean sea ice volume: What explains its recent depletion?, J. Geophys. Res., 110, C01002, doi:10.1029/2004JC002282.

Rothrock, D. A., Y. Yu, and G. A. Maykut (1999), Thinning of the Arctic sea ice cover, Geophys. Res. Lett., 26, 3469-3472.

Rothrock, D., J. Zhang, and Y. Yu (2003), The Arctic ice thickness of the 1990s: A consistent view from observations and models, J. Geophys. Res., 108(C3), 3083, doi:10.1029/2001JC001208.

Simmons, A. J., and J. K. Gibson (2000), The ERA-40 project plan, Proj. Rep. Ser. 1, 63 pp., Eur. Cent. for Medium-Range Weather Forecasts, Reading, U.K.

Smith, D. M. (1998), Recent increase in the length of the melt season of perennial Arctic sea ice, Geophys. Res. Lett., 25, 655-658.

Stroeve, J. C., M. C. Serreze, F. Fetterer, T. Arbetter, W. Meier, J. Maslanik, and K. Knowles (2005), Tracking the Arctic's shrinking ice cover Another extreme September minimum in 2004, Geophys. Res. Lett. 32, L04501, doi:10.1029/2004GL021810.

Thorndike, A. S., D. A. Rothrock, G. A. Maykut, and R. Colony (1975) The thickness distribution of sea ice, J. Geophys. Res., 80, 4501-4513. Vowinckel, E., and S. Orvig (1970), The climate of the North Pole Basin, in Climates of the Polar Regions, World Surv. Climatol., vol. 14, edited by S. Orvig, pp. 1-37, Elsevier, New York.
Wensnahan, M., and D. A. Rothrock (2005), Sea ice draft from submarinebased sonar: Establishing a consistent record from analog and digitally recorded data, Geophys. Res. Lett., 32, L11502, doi:10.1029/ 2005GL022507.

Wilchinsky, A. V., D. L. Feltham, and P. A. Miller (2006), A multi-layer sea ice model accounting for sliding friction, J. Phys. Oceanogr., 36(9), $1719-1738$

Yu, Y., G. A. Maykut, and D. A. Rothrock (2004), Changes in the thickness distribution of Arctic sea ice between 1958-1970 and 1993-1993, J. Geophys. Res., 109, C08004, doi:10.1029/2003JC001982.

Zhang, J., W. D. Hibler III, M. Steele, and D. A. Rothrock (1998a), Arctic ice-ocean modeling with and without climate restoring, J. Phys. Oceanogr., 28, 191-217.

Zhang, J., D. A. Rothrock, and M. Steele (1998b), Warming of the Arctic Ocean by a strengthened Atlantic inflow: Model results, Geophys. Res. Lett., 25, 1745-1748.

Zhang, J., D. Rothrock, and M. Steele (2000), Recent changes in Arctic sea ice: The interplay between ice dynamics and thermodynamics, J. Clim., 13, 3099-3114

Zhang, X., and J. E. Walsh (2006), Toward a seasonally ice-covered Arctic Ocean: Scenarios from the IPCC AR4 model simulations, J. Clim., 19, $1730-1747$.

D. L. Feltham, British Antarctic Survey, High Cross, Madingley Road, Cambridge CB3 0ET, UK. (dlf@cpom.ucl.ac.uk)

S. W. Laxon, Centre for Polar Observation and

Modelling, Department of Earth Sciences, University College London, Gower Street, London, WC1E 6BT, UK. (swl@cpom.ucl.ac.uk)

P. A. Miller, Department of Physical Geography and Ecosystems Analysis, Lund University, S-22364, Sweden. (paul.miller@nateko.lu.se) 